\title{
Condiciones sanitarias de los comedores comunitarios del conurbano de Buenos Aires, Argentina
}

\author{
Julia Arango, ${ }^{1}$ Adela Agostini, ${ }^{1}$ Alejandro Silvestre, ${ }^{1}$ \\ Marcela Yaafar, ${ }^{1}$ Clara López ${ }^{1}$ e Hilda Fishmann ${ }^{1}$
}

RESUMEN Debido a la importancia que la inocuidad de los alimentos entraña para la salud pública, se procuró determinar la calidad microbiológica de los alimentos que consumen los usuarios de los comedores comunitarios del conurbano de Buenos Aires, Argentina. Se trata de un estudio descriptivo, cuyo universo lo conformaron tres municipios con indices medianos y altos de pobreza, de los que se extrajo al azar una muestra de 52 comedores. La información se recolectó desde abril de 1994 hasta abril de 1995 inclusive, por medio de encuestas, observaciones directas y análisis microbiológicos del agua y los alimentos servidos. Los análisis del agua y los alimentos se ajustaron, respectivamente, a las recomendaciones del Código Alimentario Argentino y de la Comisión Internacional de Especificaciones Microbiológicas para Alimentos. Los resultados se interpretaron según los valores para alimentos cocidos acordados por el Grupo de Trabajo de Control de Alimentos. La parte microbiológica del estudio mostró que en 28 (54\%) de los comedores la comida o el agua era inadecuada y en 11 (21\%), ambas eran inadecuadas. Bacillus cereus fue la bacteria patógena que se encontró con mayor frecuencia en los alimentos analizados. Los factores significativamente asociados con condiciones microbiológicas insatisfactorias de las comidas y el agua fueron no desinfectar el agua $(\mathrm{P}=0,009)$, la falta de higiene en el ambiente $(\mathrm{P}=0,03)$, la presencia de roedores e insectos $(\mathrm{P}=0,05)$, el sistema de provisión de materias primas $(\mathrm{P}=0,01)$ y un número de usuarios menor de $100(\mathrm{P}=0,008)$. Se concluyó que la desinfección del agua y la limpieza general de los comedores son medidas que pueden implantarse por medio de intervenciones educativas en materia de higiene y manipulación de alimentos dirigidas a los encargados y empleados de los comedores. Los resultados obtenidos también apoyan la conveniencia de incluir la evaluación sanitaria de los alimentos entre los criterios de evaluación general de los programas de asistencia alimentaria.

En la Argentina hay sectores de la población cuya pobreza llega a impedirles el acceso a una alimentación mínima $(1,2)$. Por lo tanto, acuden a comedores comunitarios organizados por el Estado (por conducto de los ministerios de bienestar social o educa-

\footnotetext{
1 Universidad de Buenos Aires, Departamento de Medicina Preventiva y Salud Pública. Dirección postal: Cho-rroarín 280, 1427 Buenos Aires, Argentina.
}

ción), por iniciativas particulares o por autogestión de la comunidad (3). En esos comedores, que suelen estar localizados en sitios improvisados - como escuelas, hogares de niños, instituciones civiles o religiosas y domicilios particulares - se preparan comidas y se sirven, por lo general gratuitamente, a personas pobres.

Varios autores (4-6) han estudiado los alimentos servidos en esos comedores desde el punto de vista nutricio- nal y alimentario, así como su valor estratégico, como parte de las políticas sociales del Estado. Por el contrario, no parecen haberse realizado estudios de la inocuidad de los alimentos servidos, desde el punto de vista microbiológico. En ese sentido, un alimento se considera inocuo según la carencia de agentes patógenos; es decir, cuando las concentraciones de productos tóxicos, toxinas microbianas y microorganismos patógenos no superan los valo- 
res máximos permitidos (7). Los antecedentes de los estudios microbiológicos consultados (8-13) se refieren a la preparación de alimentos a gran escala $\mathrm{y}$ en pequeños comercios, sobre todo vinculados con la aparición de brotes en estos últimos.

Los alimentos preparados y servidos sin criterios de control microbiológico representan para la salud pública posibles riesgos que es necesario conocer y prevenir. Por lo tanto, esta investigación se llevó a cabo con el propósito de determinar la calidad microbiológica de los alimentos que consumen los usuarios de los comedores comunitarios del conurbano de Buenos Aires, Argentina, y su relación con las variables de riesgo que se enumeran en la sección de Materiales y métodos.

\section{MATERIALES Y MÉTODOS}

Este estudio descriptivo se llevó a cabo durante el período comprendido entre abril de 1994 y abril de 1995, inclusive. El universo se compuso de tres municipios con índices medianos $\mathrm{y}$ altos de pobreza registrados en el Instituto Nacional de Estadística y Censos (INDEC) (2). En los tres municipios se localizaron 157 instituciones de asistencia que tenían comedores comunitarios (3), en los cuales cuatro encuestadores previamente capacitados recolectaron información sobre las características de los beneficiarios, y las condiciones físicas y dotación de los comedores. La información se obtuvo por medio de entrevistas con los encargados y observación directa.

Se encuestó asimismo a 361 concurrentes o a familiares de estos mayores de 12 años (dos por comedor, como mínimo) para determinar si los beneficiarios calificaban como individuos con necesidades básicas insatisfechas. Se consideró que cumplían con ese criterio quienes vivían en situaciones como las siguientes: en viviendas con índices de hacinamiento de más de tres personas por habitación o que no tenían servicio sanitario de ningún tipo; en un grupo doméstico cuya tasa de dependencia económica era de tres personas o más desempleadas por cada miembro que trabajaba; o si había en la vivienda algún niño de edad escolar que no asistiera a la escuela.

Las variables estudiadas correspondieron a la organización, estructura física e higiene de los comedores. Los resultados obtenidos se evaluaron en función del cumplimiento de los requisitos mínimos que se describen a continuación.

En lo que respecta a la organización, esta se consideró adecuada si en su gestión figuraban dirigentes con autoridad y responsabilidad claramente establecidas por la institución patrocinadora de cada comedor. La estructura física se inspeccionó visualmente para determinar si contaba con instalaciones y equipo apropiados para cocina, comedor y servicios sanitarios; si las paredes, pisos y techos tenían algún revestimiento y eran fáciles de limpiar; si estaban en buenas condiciones los fregaderos, grifos y cañerías del agua en las cocinas, y los inodoros en los cuartos de servicio sanitario.

La higiene general se evaluó aplicando los criterios para la inspección de establecimientos donde se elaboran alimentos, establecidos por la Comisión del Códex Alimentarius, que patrocinan la Organización de las Naciones Unidas para la Agricultura y la Alimentación (FAO) y la Organización Mundial de la Salud (OMS). ${ }^{2}$

En la cocina se observó el grado de limpieza de mesas de trabajo, utensilios, pisos y cielo raso, y el orden y la limpieza del refrigerador. También se notó si había aberturas, sumideros inundados, residuos en lugares dispersos y fuera de los recipientes, si a estos les faltaban las tapas, si había indicios de roedores o insectos $y$, en los encargados de cocina, si su vestimenta era adecuada y limpia.

Los 130 comedores que cumplían con el requisito de asistir a personas con necesidades básicas insatisfechas se clasificaron en ocho bloques en función de su organización, estructura

\footnotetext{
1987, ALINORM 87-13 y 1993, Informe de la $26 a$ Reunión del Códex Alimentarius sobre Higiene de los Alimentos, Washington, DC, 1 a 5 de marzo de 1993.
}

edilicia e higiene (cada una categorizada como buena o mala) y se extrajo una muestra aleatoria proporcional de 52 para el estudio. Entre junio de 1994 y abril de 1995 se visitaron por segunda vez los comedores seleccionados. Se volvió a entrevistar a los encargados para obtener pormenores sobre las características de cada edificio; número y estado de baños, cocinas, comedores y equipo correspondiente; dotación de agua fría y caliente; disponibilidad de jabón y papel higiénico en los baños; sistemas de obtención y almacenamiento de víveres; preparación de menús; forma de disponer de los residuos líquidos y sólidos; métodos de limpieza; número y características de los usuarios; presencia en los 15 días anteriores de usuarios con vómitos o diarrea, y algunos otros detalles.

En esa oportunidad se recolectaron muestras de comidas listas para servir o ya servidas durante el almuerzo, por ser la comida diaria más concurrida. Cuando ello no fue posible, se tomaron muestras con hisopos de los restos que quedaban en los platos inmediatamente después de la comida, frente al comensal. Se tomó también una muestra de agua de cada comedor. Todas las muestras se empacaron refrigeradas y se enviaron, el mismo día en que se recogieron, al laboratorio del Área de Tecnología, Protección e Inspección Veterinaria de Alimentos de la Facultad de Ciencias Veterinarias de la Universidad de Buenos Aires.

El análisis microbiológico del agua se realizó según las recomendaciones del Código Alimentario Argentino (14) que establece un límite de un número más probable (NMP) de tres o menos coliformes en una muestra de $100 \mathrm{~mL}$ cultivada a $37{ }^{\circ} \mathrm{C}$ por $48 \mathrm{~h}$ en caldo de MacConkey o de laurilsulfato. Además, debe ser negativa a Escherichia coli y Pseudomonas aeruginosa. En el caso de bacterias mesófilas evaluadas por recuento en plato de agar $\left(24 \mathrm{~h}\right.$ a $\left.37^{\circ} \mathrm{C}\right)$, se permite un máximo de 500 unidades formadoras de colonias por mililitro.

Los alimentos se analizaron siguiendo las recomendaciones de la Comisión Internacional de Especificaciones Microbiológicas para Alimentos $(15,16)$. Los resultados se interpreta- 
ron de acuerdo con los valores para alimentos cocidos acordados por el Grupo de Trabajo Control de Alimentos, ${ }^{3}$ constituido por representantes de la Municipalidad de Buenos Aires y de laboratorios privados, ya que el Código Alimentario Argentino no establecía normas para las comidas que fueron objeto de este estudio. La presencia de Clostridium perfringens se evaluó según las normas francesas para carnes cocidas (8). En cuanto a coliformes fecales, se recurrió a los valores propuestos por Dragoni (9) para los rellenos cocidos de canelones y otras pastas. En el cuadro 1 se presentan las características evaluadas y se resumen los métodos microbiológicos y los criterios o límites de aceptabilidad.

Para la recolección de información, el grupo de trabajo de esta investigación diseñó instrumentos que consistían en cuestionarios de preguntas cerradas con opciones múltiples para los datos cualitativos. Parte de la información se validó por comparación con la que se obtuvo de las instituciones de las que dependían los comedores, es decir, de los Consejos Escolares del Ministerio de Educación de la Provincia de Buenos Aires, municipalidades de cada partido y otras.

La significación de las distribuciones de valores sobre la calidad de las comidas y el agua en función de las variables estudiadas se evaluó por medio de la prueba de ji cuadrado $\left(\chi^{2}\right)$ con corrección de Yates. El valor de $P=0,05$ se fijó como límite de la significación. Para el procesamiento de datos y su análisis se usó el programa computadorizado Epi Info.

\section{RESULTADOS}

De la muestra de comedores evaluados, 59,6\% operaban en escuelas de educación primaria y diferenciales, ${ }^{4}$

\footnotetext{
3 Segunda propuesta, 15 de marzo de 1993. Norma de trabajo, Municipalidad de Buenos Aires, Servicio Nacional de Sanidad Animal. (Documento inédito.)

4 Escuelas especiales para niños con trastornos del desarrollo psicológico.
}

CUADRO 1. Criterios para la evaluación microbiológica de la inocuidad de los alimentos servidos en comedores comunitarios, Buenos Aires, 1995

\begin{tabular}{|c|c|c|}
\hline Microorganismo & Método & $\begin{array}{l}\text { Valor máximo } \\
\text { permitido UFC/g }\end{array}$ \\
\hline Bacterias aerobias mesófilas & Recuento en plato de agar, $48 \mathrm{~h}$, a $35^{\circ} \mathrm{C}$ & $5 \times 10^{4}$ \\
\hline Bacterias coliformes & Agar VRBA, $25 \mathrm{~h}$, a $32{ }^{\circ} \mathrm{C}$ & $1 \times 10^{3}$ \\
\hline Bacterias coliformes fecales & Agar VRBA, $24 \mathrm{~h}$, a $44{ }^{\circ} \mathrm{C}$ & $1 \times 10^{2}$ \\
\hline Escherichia coli & $\begin{array}{l}\text { Caldo RM-VP, caldo triptona, agar citrato de } \\
\text { Simmons, } 24 \text { h a } 35^{\circ} \mathrm{C}\end{array}$ & Ausencia \\
\hline Enterobacterias totales & Agar VRBG, $24 \mathrm{~h}$, a $35^{\circ} \mathrm{C}$ & $1 \times 10^{3}$ \\
\hline Clostridium perfringens & Agar TSN $24 \mathrm{~h}$, a $35^{\circ} \mathrm{C}$ & 10 \\
\hline Staphylococcus aureus & $\begin{array}{l}\text { Agar Baird Parker } 48 \text { h, a } 35^{\circ} \mathrm{C} \text { confirmación } \\
\text { por coagulación }\end{array}$ & $1 \times 10^{2}$ \\
\hline Bacillus cereus & $\begin{array}{l}\text { Agar de yema de huevo, polimixina y rojo fenol } \\
\text { según Mossel } 24 \mathrm{~h} \text {, a } 35-37^{\circ} \mathrm{C}\end{array}$ & Ausencia \\
\hline Salmonella enteritidis & $\begin{array}{l}\text { Medio de enriquecimiento caldo lactosado, } \\
\text { enriquecimiento selectivo en caldo selenito, } \\
\text { aislamiento en agar verde brillante y agar } \\
\text { Salmonella-Shigella }\end{array}$ & Ausencia en $25 \mathrm{~g}$ \\
\hline
\end{tabular}

$\overline{\mathrm{UFC}}=$ unidades formadoras de colonias; VRBA = violeta rojo bilis agar; RM-VP = rojo metilo - Voges Proskauer; VRBG $=$ violeta rojo bilis glucosa; TSN = triptona sulfito neomicina.

$11,5 \%$ en jardines de infantes y $7,7 \%$ en centros para personas jubiladas. El resto de los comedores $(21,2 \%)$ estaban localizados en casas particulares, sindicatos e instituciones religiosas.

Se encontró la siguiente distribución de edad entre los beneficiarios: 7577 niños menores de 13 años; 21 jóvenes de 13 a 20 años; 29 adultos de 21 a 65 años, y 203 de 66 y más años. El número diario de asistentes por comedor osciló de 17 a 850, con un promedio de 149 , mediana de 100 y modas de 120 y 200.

En lo que se refiere a las características físicas de los comedores, predominaba la construcción de mampostería combinada con láminas de fibrocemento y madera. En dos de ellos faltaban las puertas y ventanas. Todos los comedores contaban con un ambiente destinado a la cocina, pero en dos de estas cocinas no había fregadero, tres carecían de mesa para la preparación de alimentos y una no tenía refrigerador. En 20 edificios en los que no existía una habitación asignada para su uso como comedor, las comidas se servían en aulas, salones de actos o de reunión, o en los pasillos. En todos los comedores había personal encargado de servir los alimentos.

En el marco propio de las pautas de cada institución, la mayoría facilitaba el acceso gratuito. Solo en $6 \%$ de los comedores se requería el pago de una contribución. Las madres de los niños que eran admitidos a los comedores podían contribuir con su trabajo.

En todos los comedores había cuartos de baño. La mayor parte de ellos eran de uso común para toda la institución. Solo la mitad de ellos proveían papel higiénico y jabón, si se pedían a los encargados.

Se analizó un total de 94 muestras de comida servida. Se obtuvo una muestra en cada uno de 13 comedores, dos muestras en 36 comedores y tres muestras en los 3 restantes. De estas, $75,5 \%$ cumplían satisfactoriamente con las características mínimas de inocuidad de los alimentos. Sobre la base de los resultados del estudio microbiológico, 28 comedores proporcionaron comida o agua con distintos grados de contaminación inadecuada, mientras que en 11 comedores ambas eran inadecuadas. Bacillus cereus fue la bacteria patógena que se aisló con mayor 
frecuencia en los alimentos. Los datos correspondientes a las comidas que resultaron insatisfactorias se muestran en el cuadro 3.

Las variables que mostraron una asociación significativa con la calidad insatisfactoria de los alimentos fueron las prácticas de desinfección del agua $(P=0,009)$; la higiene de los comedores $(P=0,03)$; la infestación con roedores e insectos $(P=0,05)$; el sistema de compra y suministro de los alimentos crudos $(P=0,01)$, y un número de usuarios menor de $100(P=0,008)$ (cuadro 2).

\section{DISCUSIÓN}

El número de asistentes diarios a los comedores se ha mantenido estable por muchos años, si bien en algunos casos ha tendido a aumentar, según informaron los encargados. Teniendo en cuenta que $96 \%$ de los usuarios de los comedores comunitarios suelen ser menores de 13 años, se destaca la importancia de una manipulación apropiada de los alimentos, puesto que se trata de un grupo de edad muy susceptible a las infecciones intestinales.

La presencia de bacterias en los alimentos analizados señala que había problemas de higiene con el proceso de preparación y manipulación o bien una cocción insuficiente de los alimentos. La inspección de los comedores resultó apropiada a fin de determinar si la higiene era adecuada, porque los resultados no satisfactorios de las comidas coincidieron con la calificación de la higiene como mala. Sería útil estudiar la forma en que se manipulan los alimentos antes de llegar a las cocinas de los comedores comunitarios. En este sentido cabe notar que las compras descentralizadas, es decir, hechas independientemente por cada institución, se asociaron más frecuentemente con alimentos y agua inocuos $(P=0,01)$.

Solo en dos ocasiones hubo que recurrir al hisopado del plato para la toma de muestras (guiso y arroz con salchichas según el orden de mención en el cuadro 3). Esta baja frecuencia no permite sustentar hipótesis acerca del
CUADRO 2. Proporción de comedores comunitarios $(n=52)$ que servían alimentos y agua inocuos según las variables de riesgo estudiadas y valores obtenidos con pruebas estadísticas, Buenos Aires, 1995

\begin{tabular}{|c|c|c|c|c|c|c|c|}
\hline \multirow[b]{2}{*}{ Variable } & \multirow[b]{2}{*}{ No. } & \multicolumn{3}{|c|}{$\begin{array}{l}\text { Comedores con alimentos } \\
\text { inocuos }\end{array}$} & \multicolumn{3}{|c|}{$\begin{array}{c}\text { Comedores con alimentos } \\
\text { y agua }\end{array}$} \\
\hline & & $\%$ & $x^{2}$ & $P$ & $\%$ & $x^{2}$ & $P$ \\
\hline \multicolumn{8}{|l|}{ Organización } \\
\hline Adecuada & 40 & 70,0 & 1,63 & 0,20 & 47,5 & 0,00 & 0,97 \\
\hline Inadecuada & 12 & 50,0 & & & 41,6 & & \\
\hline \multicolumn{8}{|l|}{ Estructura física } \\
\hline Adecuada & 21 & 71,4 & 0,57 & 0,45 & 47,6 & 0,03 & 0,84 \\
\hline Inadecuada & 31 & 61,2 & & & 45,1 & & \\
\hline \multicolumn{8}{|l|}{ Higiene } \\
\hline Adecuada & 31 & 66,6 & 0,39 & 0,53 & 58,0 & 4,38 & 0,03 \\
\hline Inadecuada & 21 & 58,0 & & & 28,5 & & \\
\hline \multicolumn{8}{|l|}{ Salón comedor } \\
\hline Disponible & 32 & 65,6 & 0,02 & 0,96 & 37,5 & 2,51 & 0,11 \\
\hline No disponible & 20 & 65,0 & & & 60,0 & & \\
\hline \multicolumn{8}{|l|}{ Despensa } \\
\hline Disponible & 33 & 63,6 & 0,12 & 0,72 & 45,4 & 0,02 & 0,89 \\
\hline No disponible & 19 & 68,4 & & & 47,3 & & \\
\hline \multicolumn{8}{|c|}{ Tela metálica en aberturas } \\
\hline Sí & 10 & 70,0 & 0,00 & 0,97 & 30,0 & 0,62 & 0,43 \\
\hline No & 42 & 64,2 & & & 50,0 & & \\
\hline \multicolumn{8}{|l|}{ Abasto de agua } \\
\hline Por cañería & 21 & 71,4 & 0,56 & 0,45 & 42,8 & 0,02 & 0,88 \\
\hline Por otro sistema & 31 & 61,2 & & & 41,9 & & \\
\hline \multicolumn{8}{|l|}{ Calidad del agua } \\
\hline Potable & 31 & 74,1 & 2,63 & 0,10 & 74,1 & - & - \\
\hline No potable & 21 & 53,3 & & & 0,0 & & \\
\hline \multicolumn{8}{|l|}{ Con tanque de agua } \\
\hline Sí & 49 & 65,3 & 0,33 & 0,56 & 44,8 & 0,02 & 0,89 \\
\hline No & 3 & 66,6 & & & 66,6 & & \\
\hline \multicolumn{8}{|c|}{ Limpieza del tanque de agua } \\
\hline Adecuada & 45 & 66,6 & 0,00 & 0,94 & 46,6 & 0,05 & 0,82 \\
\hline Inadecuada & 7 & 57,1 & & & 42,8 & & \\
\hline \multicolumn{8}{|l|}{ Desinfección del agua } \\
\hline Adecuada & 35 & 74,2 & 3,74 & 0,05 & 60,0 & 6,64 & 0,009 \\
\hline Inadecuada & 17 & 47,0 & & & 17,6 & & \\
\hline \multicolumn{8}{|l|}{ Agua caliente } \\
\hline Disponible & 35 & 60,0 & 0,74 & 0,39 & 48,5 & 0,25 & 0,61 \\
\hline No disponible & 17 & 76,4 & & & 41,1 & & \\
\hline \multicolumn{8}{|c|}{ Destino de líquidos residuales } \\
\hline Pozo negro & 38 & 65,7 & 0,01 & 0,99 & 47,3 & 0,05 & 0,81 \\
\hline Cloaca & 11 & 63,6 & & & 45,4 & & \\
\hline Otro & 3 & 66,6 & & & 33,3 & & \\
\hline \multicolumn{8}{|c|}{ Lavatorio en cuarto de baño } \\
\hline Sí & 46 & 65,2 & 0,14 & 0,69 & 47,8 & 0,05 & 0,81 \\
\hline No & 6 & 66,6 & & & 33,3 & & \\
\hline \multicolumn{8}{|l|}{ Cocina azulejada } \\
\hline Sí & 38 & 65,7 & 0,05 & 0,82 & 50,0 & 0,36 & 0,54 \\
\hline No & 14 & 64,2 & & & 35,7 & & \\
\hline \multicolumn{8}{|l|}{ Mesas de cocina } \\
\hline Disponibles & 49 & 67,3 & 0,33 & 0,56 & 48,9 & - & - \\
\hline No disponibles & 3 & 33,3 & & & 0,0 & & \\
\hline
\end{tabular}


CUADRO 2. (Continuación)

\begin{tabular}{|c|c|c|c|c|c|c|c|}
\hline \multirow[b]{2}{*}{ Variable } & \multirow[b]{2}{*}{ No. } & \multicolumn{3}{|c|}{$\begin{array}{l}\text { Comedores con alimentos } \\
\text { inocuos }\end{array}$} & \multicolumn{3}{|c|}{$\begin{array}{c}\text { Comedores con alimentos } \\
\text { y agua inocuos }\end{array}$} \\
\hline & & $\%$ & $x^{2}$ & $P$ & $\%$ & $x^{2}$ & $P$ \\
\hline \multicolumn{8}{|l|}{ Material de mesa } \\
\hline $\begin{array}{l}\text { Impermeable } \\
\text { Madera }\end{array}$ & $\begin{array}{l}37 \\
15\end{array}$ & $\begin{array}{l}70,2 \\
53,3\end{array}$ & 1,35 & 0,24 & $\begin{array}{l}45,9 \\
46,6\end{array}$ & 0,00 & 0,96 \\
\hline \multicolumn{8}{|l|}{ Congelador } \\
\hline $\begin{array}{l}\text { Disponible } \\
\text { No disponible }\end{array}$ & $\begin{array}{l}26 \\
26\end{array}$ & $\begin{array}{l}53,8 \\
76,9\end{array}$ & 3,06 & 0,08 & $\begin{array}{l}38,4 \\
53,8\end{array}$ & 1,24 & 0,26 \\
\hline \multicolumn{8}{|c|}{ Método de recoger la basura } \\
\hline $\begin{array}{l}\text { En bolsas plásticas } \\
\text { Otro sistema }\end{array}$ & $\begin{array}{r}46 \\
6\end{array}$ & $\begin{array}{l}67,3 \\
50,0\end{array}$ & 0,15 & 0,69 & $\begin{array}{l}50,0 \\
16,6\end{array}$ & 1,22 & 0,26 \\
\hline \multicolumn{8}{|l|}{ Recolección de basura } \\
\hline $\begin{array}{l}\text { Diaria } \\
\text { No diaria }\end{array}$ & $\begin{array}{l}28 \\
24\end{array}$ & $\begin{array}{l}60,7 \\
70,8\end{array}$ & 0,58 & 0,44 & $\begin{array}{l}35,7 \\
58,3\end{array}$ & 1,33 & 0,24 \\
\hline \multicolumn{8}{|l|}{ Responsable de limpieza } \\
\hline $\begin{array}{l}\text { Remunerado } \\
\text { No remunerado }\end{array}$ & $\begin{array}{r}47 \\
5\end{array}$ & $\begin{array}{l}65,9 \\
60,0\end{array}$ & 0,05 & 0,81 & $\begin{array}{r}51,0 \\
0,0\end{array}$ & - & - \\
\hline \multicolumn{8}{|l|}{$\begin{array}{l}\text { Presencia de roedores o } \\
\text { insectos }\end{array}$} \\
\hline $\begin{array}{l}\text { No } \\
\text { Sí }\end{array}$ & $\begin{array}{l}27 \\
25\end{array}$ & $\begin{array}{l}59,2 \\
72,9\end{array}$ & 0,93 & 0,33 & $\begin{array}{l}33,3 \\
60,0\end{array}$ & 3,71 & 0,05 \\
\hline \multicolumn{8}{|l|}{ Proveedor de platos } \\
\hline $\begin{array}{l}\text { Un encargado } \\
\text { Los usuarios }\end{array}$ & $\begin{array}{l}39 \\
13\end{array}$ & $\begin{array}{l}64,1 \\
69,2\end{array}$ & 0,00 & 1,00 & $\begin{array}{l}46,1 \\
46,1\end{array}$ & 0,00 & 1,0 \\
\hline \multicolumn{8}{|l|}{ Lavador de platos } \\
\hline $\begin{array}{l}\text { Un encargado } \\
\text { Los usuarios }\end{array}$ & $\begin{array}{l}40 \\
12\end{array}$ & $\begin{array}{l}60,0 \\
83,3\end{array}$ & 1,31 & 0,25 & $\begin{array}{l}40,0 \\
66,6\end{array}$ & 1,68 & 0,19 \\
\hline \multicolumn{8}{|l|}{ Suministro de víveres } \\
\hline $\begin{array}{l}\text { Por el municipio } \\
\text { Por la institución } \\
\text { Por otros donantes }\end{array}$ & $\begin{array}{l}13 \\
26 \\
13\end{array}$ & $\begin{array}{l}53,8 \\
73,0 \\
61,5\end{array}$ & 1,53 & 0,46 & $\begin{array}{l}23,0 \\
65,3 \\
30,7\end{array}$ & 7,89 & 0,01 \\
\hline \multicolumn{8}{|l|}{$\begin{array}{l}\text { Compra adicional por } \\
\text { encargados }\end{array}$} \\
\hline $\begin{array}{l}\text { Posible } \\
\text { No posible }\end{array}$ & $\begin{array}{l}22 \\
30\end{array}$ & $\begin{array}{l}72,7 \\
60,0\end{array}$ & 0,40 & 0,52 & $\begin{array}{l}40,9 \\
50,0\end{array}$ & 0,42 & 0,51 \\
\hline \multicolumn{8}{|l|}{ Comidas diarias } \\
\hline $\begin{array}{l}\text { merienda } \\
\text { Desayuno y almuerzo } \\
\text { Almuerzo } \\
\text { Desayuno y merienda }\end{array}$ & $\begin{array}{r}39 \\
4 \\
8 \\
1\end{array}$ & $\begin{array}{r}56,4 \\
75,0 \\
100,0 \\
100,0\end{array}$ & 5,70 & 0,12 & $\begin{array}{r}41,0 \\
50,0 \\
62,5 \\
100,0\end{array}$ & 2,46 & 0,48 \\
\hline \multicolumn{8}{|l|}{ Menú } \\
\hline $\begin{array}{l}\text { Fijo } \\
\text { Variable }\end{array}$ & $\begin{array}{l}23 \\
29\end{array}$ & $\begin{array}{l}56,5 \\
72,4\end{array}$ & 1,52 & 0,21 & $\begin{array}{l}43,4 \\
48,2\end{array}$ & 0,12 & \\
\hline \multicolumn{8}{|l|}{ Asistentes diarios } \\
\hline $\begin{array}{c}0-99 \\
100-199 \\
200 \text { o más }\end{array}$ & $\begin{array}{l}24 \\
15 \\
13\end{array}$ & $\begin{array}{l}58,3 \\
60,0 \\
84,6\end{array}$ & 2,84 & 0,24 & $\begin{array}{l}57,1 \\
40,0 \\
76,9\end{array}$ & 6,77 & 0,03 \\
\hline
\end{tabular}

riesgo vinculado con la vajilla y la saliva del consumidor.

El alto porcentaje $(40,3 \%)$ de comedores con agua microbiológicamente inaceptable hace que sea recomenda- ble averiguar por qué no se cumplía con la desinfección, que era responsabilidad de los encargados. Cabe preguntarse si ello se debió a la falta de información, de voluntad o de posibi- lidad de llevar a cabo la tarea. La presencia de roedores e insectos apoyaría los supuestos de falta de percepción y de voluntad.

Bacillus cereus fue el más frecuente de los microorganismos patógenos detectados, hallazgo importante debido a la utilización regular de cereales que están generalmente implicados como fuente de infección. Siendo esporógeno este bacilo, su eliminación exigiría una cocción muy prolongada de los cereales o a temperaturas muy altas.

Por otra parte, en tres comedores donde los alimentos reunían cualidades satisfactorias de inocuidad, algún usuario había tenido diarrea o vómitos en los 15 días previos a la encuesta. La baja frecuencia de síntomas y signos de enfermedad percibida por los usuarios y referida por encargados de los comedores sugiere que la metodología o variable para obtener este tipo de dato no fue adecuada y que deben suplirse de otra forma las deficiencias del sistema de vigilancia epidemiológica.

En las tres categorías de tamaño de los comedores, de acuerdo con el número de usuarios recibidos diariamente, fue similar la proporción de los que tenían buena higiene y de los que desinfectaban el agua. Esto plantea el interrogante sobre cuáles eran los factores vinculados con la mala calidad de las comidas y el agua en los comedores a los que asistían menos de 100 personas.

Dado el previsible incremento de los comedores comunitarios, cabe proponer que la calidad higiénica y sanitaria de los alimentos servidos sea incluida entre los criterios de evaluación de los programas de asistencia alimentaria. La desinfección del agua y la higiene de los comedores son variables que pueden modificarse mediante intervenciones educativas en materia de higiene y manipulación de alimentos dirigidas a los responsables de los comedores.

Agradecimiento. Los autores agradecen el subsidio proporcionado por la Secretaría de Ciencia y Técnica, Universidad de Buenos Aires, Consejo Nacional de Investigaciones Científicas, para la realización de este estudio. 
CUADRO 3. Resultados de los estudios microbiológicos de alimentos servidos en 52 comedores comunitarios, Buenos Aires, 1995

\begin{tabular}{|c|c|c|c|c|c|}
\hline \multirow[b]{2}{*}{ Comida } & \multicolumn{5}{|c|}{ Recuento de microorganismos } \\
\hline & 1 & 2 & 3 & 4 & 5 \\
\hline Arroz con leche & $7 \times 10^{5}$ & $2 \times 10^{4}$ & $1 \times 10^{3}$ & 0 & 0 \\
\hline Canelones de pollo & $1 \times 10^{7}$ & $1 \times 10^{5}$ & $1 \times 10^{7}$ & $1 \times 10^{2}$ & $1 \times 10^{4}$ \\
\hline Carne & $1 \times 10^{3}$ & $1 \times 10^{2}$ & 10 & $1 \times 10^{2}$ & \\
\hline Carne con salsa & $2 \times 10^{2}$ & $1 \times 10^{6}$ & & & \\
\hline Gelatina $^{\mathrm{a}}$ & $5 \times 10^{7}$ & $3 \times 10^{2}$ & $2 \times 10^{3}$ & 10 & $1 \times 10^{2}$ \\
\hline Guiso & $5 \times 10^{5}$ & $5 \times 10^{3}$ & $1 \times 10^{3}$ & 10 & 0 \\
\hline Guiso $^{a}$ & $5 \times 10^{4}$ & $1 \times 10^{2}$ & $1 \times 10^{2}$ & 10 & $1 \times 10^{2}$ \\
\hline Guiso & $1 \times 10^{6}$ & $1 \times 10^{4}$ & $1 \times 10^{2}$ & $1 \times 10^{2}$ & 10 \\
\hline Guiso $^{a}$ & $1 \times 10^{6}$ & $5 \times 10^{5}$ & $3 \times 10^{3}$ & 0 & $1 \times 10^{2}$ \\
\hline Guiso $^{a}$ & $5 \times 10^{5}$ & $2 \times 10^{5}$ & $2 \times 10^{4}$ & 10 & $1 \times 10^{2}$ \\
\hline Fideos con carne & $1,5 \times 10^{5}$ & $3 \times 10^{3}$ & $1,5 \times 10^{3}$ & $1 \times 10^{2}$ & $1 \times 10^{2}$ \\
\hline Flan con chocolate & $1 \times 10^{6}$ & $1 \times 10^{5}$ & $1 \times 10^{5}$ & 0 & 0 \\
\hline Hamburguesas con arroz & $2 \times 10^{4}$ & $1 \times 10^{5}$ & $2 \times 10^{2}$ & $<10$ & 0 \\
\hline Hisopado de un plato & $1 \times 10^{5}$ & $1 \times 10^{3}$ & $1 \times 10^{2}$ & 0 & 0 \\
\hline Hisopado de un plato & $5 \times 10^{5}$ & $1 \times 10^{3}$ & 0 & 0 & $1 \times 10^{3}$ \\
\hline Milanesa con puréa & $3 \times 10^{6}$ & $3 \times 10^{5}$ & $4 \times 10^{4}$ & 0 & $1 \times 10^{2}$ \\
\hline Papa y zanahoria & $5 \times 10^{5}$ & $1 \times 10^{7}$ & 0 & 0 & 0 \\
\hline Pan de carne ${ }^{a}$ & $4 \times 10^{4}$ & $1 \times 10^{2}$ & 10 & $<10$ & $1 \times 10^{2}$ \\
\hline Pan de carne & $7 \times 10^{3}$ & $5 \times 10^{5}$ & $1 \times 10^{6}$ & 0 & 0 \\
\hline Pollo al horno con papas & $1 \times 10^{2}$ & $1 \times 10^{4}$ & $1 \times 10^{2}$ & 0 & 0 \\
\hline Puré de papa & $1 \times 10^{4}$ & $6 \times 10^{4}$ & $2 \times 10^{4}$ & 0 & $1 \times 10^{2}$ \\
\hline Sémola ${ }^{\mathrm{a}}$ & $2 \times 10^{3}$ & $5 \times 10^{3}$ & $3 \times 10^{2}$ & 0 & $1 \times 10^{2}$ \\
\hline Sopa ${ }^{a}$ & $4 \times 10^{5}$ & $7 \times 10^{5}$ & $7 \times 10^{4}$ & 0 & $1 \times 10^{2}$ \\
\hline
\end{tabular}

REFERENCIAS

1. Martínez Nogueira R. La Pobreza: un programa de acción. Buenos Aires: Fundación Banco de Boston; 1992.

2. Instituto Nacional de Estadística y Censos (INDEC). La pobreza en la Argentina. Buenos Aires: INDEC; 1985. (Serie de estudios $\mathrm{N}^{\mathrm{o}} 1$ ).

3. Aparicio JE, Hernando de Pola. Guía de recursos de la comunidad. Buenos Aires: Editorial Humanitas; 1982.

4. Organización Panamericana de la Salud. Estudio sobre intervenciones alimentario-nutricionales para poblaciones de bajos ingresos en Latinoamérica y el Caribe. Washington, DC: OPS; 1990. (Cuaderno técnico 21).

5. Rúgolo E. Racionalidad en la determinación de prioridades para la asignación de recursos alimentarios. Salud Para Todos 1990;9-10:2-10.

6. Organización Panamericana de la Salud. Problemas nutricionales en países en desarrollo en las décadas de 1980 y 1990: simposio patrocinado por el Consejo Nacional de Investigaciones (EUA). Washington, DC: OPS; 1987. (Cuaderno técnico 10).

7. Musgrove P. Por una mejor alimentación: evaluación de programas destinados a mejo- rar el consumo alimentario y el estado nutricional de familias pobres en Brasil. Washington, DC: Organización Panamericana de la Salud; 1990. (Cuaderno técnico 25).

8. Commission "Évaluation de la qualité microbiologique des aliments". La qualité microbiologique des aliments: maitrise et critères. Paris: Polytechnica; 1993.

9. Dragoni I. Standards igienici nella ristorazione collettiva e commerciale. Ristoraz collet 1984;9:126-131.

10. Kaiser L, Cabello P, Montane P, Flores L. Consideraciones microbiológicas en la preparación de raciones alimenticias. Alimentos (Chile) 1984;9:27-31.

11. Ferrer MD, de Simón M, Tarragó C. Presencia de bacterias patógenas en alimentos preparados cocinados. Alimentaria. Revista de Tecnología e Higiene de los Alimentos 1992: 69-70.

12. Dantas RA, Silva M, Conceiçao C. Microbiological analysis of meals prepared in canteens. Cater Health 1988;1:23-49.

13. Sly T, Ross E. Chinese foods: relationship between hygiene and bacterial flora. J Food Prot 1982;45:115-118.
14. Argentina, Ministerio de Salud y Acción Social. Vol II: Código alimentario argentino. Buenos Aires: De la Canal y Asociados S.R.L. 1996.

15. International Commission on Microbiological Specifications for Foods. Microorganisms in foods 1: their significance and methods of enumeration. 2a. ed. Toronto: University of Toronto Press; 1978

16. Quevedo F. Nuevos procedimientos para el control higiénico de los alimentos. Buenos Aires: Centro Panamericano de Zoonosis; 1976.

Manuscrito recibido el 15 de noviembre de 1995 y aceptado en versión revisada el 13 de agosto de 1996. 
ABSTRACT Because of the importance of food safety for public health, a study was done to determine the microbiologic quality of foods provided to patrons of community dining halls in greater Buenos Aires, Argentina. The study was descriptive and was conducted in three municipalities with intermediate or high poverty indices; a sample of 52 dining halls was selected randomly from those municipalities. Information was collected from April 1994 through April 1995 by means of surveys, direct observations, and microbiologic analyses of the water and food served. Water and food analysis followed the recommendations of the Argentine Food Code and the International Commission on Microbiologic Specifications for Foods, respectively. The results were interpreted according to the values for cooked foods agreed upon by the Working Group on Food Monitoring. The microbiologic analysis revealed that $28(54 \%)$ of the dining halls had food or water of inadequate quality and $11(21 \%)$ had inadequacies in both. Bacillus cereus was the most commonly found pathogenic bacterium in the food samples analyzed. The factors that were significantly associated with unsatisfactory microbiologic conditions in the food and water were lack of disinfection of the water $(P=0.009)$, lack of hygiene in the environment $(P=0.03)$, the presence of rodents and insects $(P=0.05)$, the supply system for raw materials $(P=0.01)$, and a relatively small number of users, i.e., fewer than $100(P=0.0008)$. It was concluded that water disinfection and general clean-up of the dining halls were measures that could be put in place by providing education in the areas of hygiene and food handling to supervisors and employees. The results obtained also indicate the need to include a food safety evaluation among the general evaluation criteria for food assistance programs.

\section{Conferencia Internacional sobre Enfermedades Infecciosas Emergentes}

Fechas: 8 a 11 de marzo de 1998

Lugar: $\quad$ Hotel Marriott Marquis, Atlanta, Georgia, Estados Unidos de América

Tema: Enfermedades infecciosas emergentes

Esta Conferencia ha sido organizada por iniciativa del Comité Directivo en Enfermedades Infecciosas Emergentes y tiene el apoyo de los Centros para el Control y la Prevención de Enfermedades, de Atlanta, Georgia, Estados Unidos. La reunión consistirá en sesiones plenarias y en simposios a los que asistirán invitados especiales y donde se presentarán trabajos sobre vigilancia, epidemiología, investigación, notificación de casos, actividades de control y medidas apropiadas para situaciones de urgencia. Los resúmenes deberán referirse a las enfermedades (nuevas, reemergentes o resistentes al tratamiento) de mayor interés desde el punto de vista de la salud pública, particularmente las transmitidas por artrópodos, las enfermedades tropicales, las enfermedades de transmisión sexual y las infecciones respiratorias, intrahospitalarias, pediátricas y oportunistas.

La fecha límite para enviar resúmenes es el 31 de octubre de 1997. La inscripción estará limitada a 2500 participantes.

Información:

Teléfono: (202) 9429248

Correo electrónico: meetingingot@asmusa.org 